\title{
Beyond the bench: A conversation with Andrew Whitehouse
}

\section{BY DELIA O'HARA}

24 NOVEMBER 2021

Working as a speech-language pathologist back in the early 2000s, Andrew Whitehouse saw one family after another struggling to get good care for their autistic children, some of them pursuing pricey, unproven therapies. One family scrimped to pay to have their autistic child strapped to a machine that they had been told would "literally rewire the brain," he says, but actually, "all it did was beep."

Whitehouse, 40, decided then that he would devote his career to raising the standard of care for autism. He went to graduate school in psychology and is now professor of autism research at the University of Western Australia in Perth, where among other duties, he creates policy to help children with autism get properly diagnosed and treated. He helped develop a national guideline for Australia for diagnosing autism and is at work on a similar guideline for early-intervention protocols.

Whitehouse told Spectrum how he helps parents connect with their children, what it's like to be an identical twin and about his conservation efforts in the Outback.

\section{Spectrum: What 'big question' drives your research?}

Andrew Whitehouse: How can we conduct science and translate evidence into policy to support children who are developing differently, and their families? My professional life now revolves around connecting good science with system change, which requires evidence and advocacy.

My overwhelming feeling is that we accept, and perhaps even expect, lower standards of clinical evidence in the autism field than in almost any other. The dangers to families are so obvious - not just in terms of safety, but also in the emotional, financial and opportunity costs. Through a guideline process, we can define good practice. 


\section{Spectrum | Autism Research News}

https://staging.spectrumnews.org

My research revolves around developing and trialing new therapies. We try to contribute rigorous clinical trials to the literature, particularly in areas where there are clear evidence gaps.

\section{S: Do you work directly with families?}

AW: As a clinical researcher, yes. I'm the director of an initiative of the Telethon Kids Institute called CliniKids, where my team and I conduct randomized, controlled trials embedded in a very big, busy clinical service. Families come in from the community — or from across Australia or the world - and access services, and they also have the option of enrolling in clinical trials of new therapies.

Much of the time, I work with babies who show early behavioral signs of autism, exploring whether we will see better outcomes if we start therapies in the first year of life. Parents might notice that their babies are developing differently, but therapy typically does not start until a child gets an autism diagnosis at age 2 at the earliest.

Our therapies target 'mismatches' in communication styles between parents and children.

Parental communication is in no way a cause of autism, but parents do play a pivotal role in their baby's development. We film parents interacting with their child to help them understand the child's unique skills and abilities, and how they can best engage with the child. We have shown that babies with early signs of autism who receive such preemptive therapy from age 9 months had more advanced social communication skills than the controls, and a reduced likelihood of receiving an autism diagnosis at age 3 .

\section{S: What is your day like?}

AW: I'm up before 6 a.m. and head out for a run with my dog. My wife Jacqui and I then wrangle our daughters, ages 4 and 6 , into their school uniforms and out the door. I'm usually standing behind my computer by about 8 a.m.

My workdays are quite varied. One day I may be looking at data and writing papers, the next I might be meeting with politicians to discuss new policies. That kind of mix is perfect for me.

Like most working parents, we're a bit chaotic, but Jacqui (a cancer researcher at the same institute) and I are militant about leaving work at 5 p.m. every day so we can spend a good chunk of time with the girls before bedtime. When they're tucked in, l'll either head out to a work function or pop on to the computer for an hour or two to knock off a bit of work.

Canine connection: An Aussie rules football fan, Andrew Whitehouse typically starts his day running with his dog, Abbie. 


\section{S: What's your secret to juggling these varied roles?}

AW: It's helpful to be able to switch your mind to a new task as soon the opportunity presents itself. I wrote a popular science book (published in 2013), "Will Mozart Make My Baby Smart?" That taught me a great deal about how to grab writing time whenever I can. And wearing different 'hats' provides insights and sparks ideas.

\section{S: Do you listen to music while you work?}

AW: Yes, all kinds - '90s rock, pop, classical music. It took me years to train myself to not get distracted by music, and now I struggle to work without it.

\section{S: Are you active on social media?}

AW: I confess to being a very slow adopter of new technology, but my team has a Facebook account I think we use to good effect. We post a video series we've had since 2016 called "60 Second Science," in which we present the findings of a recent paper in lay language. Most episodes get several thousand views, which is a lovely way to connect with the autism community around the world.

\section{S: Does your lab have any cherished traditions?}

AW: We do have one, called CliniTudes, a portmanteau of CliniKids and gratitude. Every couple of weeks, my CliniKids team of 50 clinicians, scientists and administrators all relate something we noticed someone else on our team doing that was kind, brave or just bloody funny. It might be helping with a complex assessment or a small task that might otherwise go unnoticed. Sometimes, it's simply showering accolades on the person who brought in donuts.

\section{S: What led you to work on autism?}

AW: I was 19 or 20 years old, training to be a speech-language pathologist, when the child of a family friend was diagnosed on the spectrum, back when that was not common. The family had significant struggles obtaining appropriate supports. Most of all, I remember the moments of extraordinary connection between the parents and the child, and that has driven much of my work.

\section{S: What are you reading right now?}

AW: I usually have my nose in the latest issue of The New Yorker and a history book. At the moment, I'm two books into Peter Ackroyd's series, "The History of England."

\section{S: Where are you from? How did that shape you?}


AW: I'm from Perth, which is actually very isolated; an independent streak is a big part of the Western Australian identity. We're either connected to the beach or to our expansive Outback. It's very much the latter for me. There's something about the red dirt of our very ancient land that clings to the soul.

\section{S: Are you close to your parents and siblings?}

AW: Yes. I am an identical twin, and we are very identical and very close. Ben works in child protection, so our personal and professional lives overlap. We even edited a book together, a collection of essays by adults, some well known, about formative experiences in their lives. We each contributed a piece as well. We also have a sister who is 14 months older. My family and I are quite committed environmentalists and have spent much of the past 10 years revegetating degraded land out in the Australian bush - 30,000 trees planted, and counting!

\section{S: What do you do for fun?}

AW: I play the piano and the guitar. I love to write and I'm a passionate Australian rules football supporter. My emotions rise and fall with the fortunes of my beloved West Coast Eagles.

Also, thanks to my daughters, my pretend-play skills are finely tuned. I can leap from fairy princess to fire-breathing dragon with the wave of a magic wand.

Cite this article: https://doi.org/10.53053/TPQR8442 